\title{
The nanomechanical characterization and tensile test of polymer nanocomposites for bioimplants
}

Cite as: AIP Conference Proceedings 2123, 020065 (2019); https://doi.org/10.1063/1.5116992

Published Online: 17 July 2019

Alaa A. Mohammed, Emad S. Al-Hassani, and Jawad K. Oleiwi

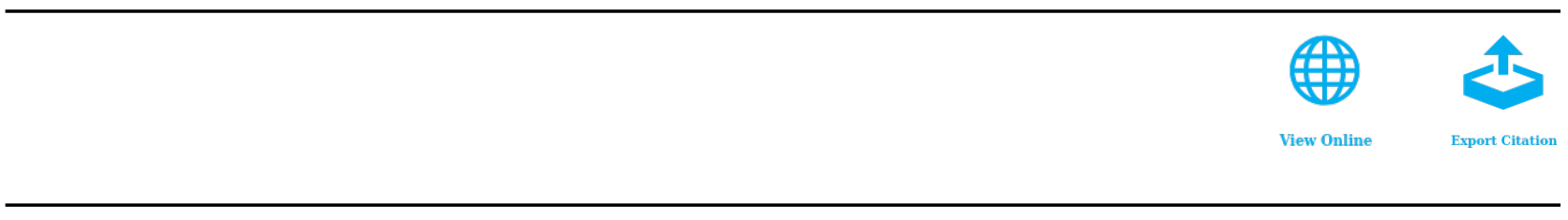

\section{Conference Proceedings}

Get $30 \%$ off all print proceedings!

\section{Enter Promotion Code PDF-30 at checkout}

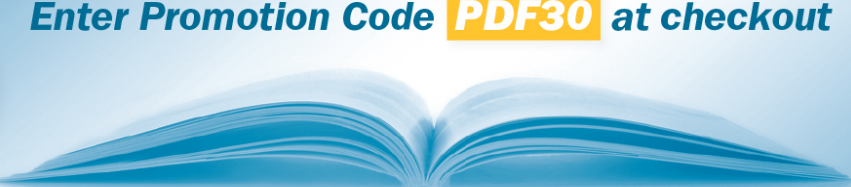




\title{
The Nanomechanical Characterization and Tensile Test of Polymer nanocomposites for Bioimplants
}

\author{
Alaa a. Mohammed ${ }^{\text {a)}}$, Emad S. Al-Hassani ${ }^{\text {b) }}$, Jawad K. Oleiwi ${ }^{\text {c) }}$ \\ Department of Materials Engineering, University of Technology (UOT), Baghdad, Iraq. \\ a) alaaabed960@gmail.com \\ ${ }^{b)}$ Corresponding author:130042@uotechnology.edu.iq \\ c)130041@uotechnology.edu.iq
}

\begin{abstract}
Nanoindentation is a powerful technique to determine various mechanical properties of materials at the nanoscale, such as for example young's modulus and hardness. Polyetheretherketone (PEEK) is a material that is widely used in medicine because its mechanical properties show excellent similarity to those of human bone. PEEK is a synthetic polymer being used increasingly as a implant material due to its iso-elastic nature and enhanced mechanical properties. This study presents the effect of PEEK specimens incorporated with $(0,0.5,1 \& 1.5) \mathrm{wt} \%$ nano hydroxyapatite (nHA) and nano titanium oxide (nTiO2) processed by compounding and hot press. The main objective of this study is to conduct a manufacturing experiment nano polyetheretherketone composite for characterization of its mechanical properties using a tensile test and nanoindentation techniques of mechanical tests. The results of mechanical tests exhibit improvments of youngs modulus, hardness and ultimate tensile strength at $1.5 \mathrm{wt} \%$ for two types of reinforcement but the higher values obtained when reinforced by (nHA). In addition the elastic modulus determined by the nanoindentation technique differs from the results obtained from tensile test by (14-38)\%. The results also showed that the highest value obtained for ultimate tensile strength and hardness was (79.457Mpa, $0.3256743 \mathrm{GPa}$ ) respectively.
\end{abstract}

Key Words. Polyetheretherketone, Hydroxyapatite, Titanium dioxide, Nanoindentation, Tensile test.

\section{INTRODUCTION}

Polyetheretherketone (PEEK) is one of the most high-performance thermoplastic materials, which is a semi-crystalline thermoplastic polymer with an approximate crystallinity of 30\%-35\% [1,2]. PEEK has been used in a wide range of applications due to its outstanding properties such as superior mechanical properties, excellent wear-resistance, environmental resistance and thermal stability [3-5]. Especially, PEEK and PEEK composites used as implant materials for replacing and repairing hard tissues of human body have attracted increasing attention because of their excellent mechanical and biocompatibility properties[6-8]. Compared with traditional orthopedic implants such as metallic and ceramic implants, one of the benefits of PEEK based composites is that they could overcome the disadvantages of metallic and ceramic implants currently adopted in orthopedic application. It is well known that the modulus of the traditional orthopedic alloys and ceramic used in hard tissue reconstruction is 10-20 times greater than that of the bone. Thus, it will inevitably be a modulus of the implant mismatch with that of natural bone, thereby producing stress shielding effect, which would lead to the aseptic loosening of implants and bone loss [9]. PEEK is a polycyclic, aromatic and has a linear structure. This material is obtained as a result of the binding of ketone and ether functional groups between aryl rings and is an element which is tan-colored in its pure form [10,11] (Figure 1).

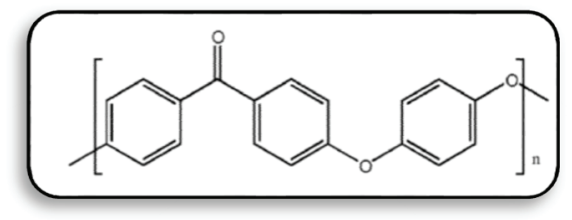

FIGURE 1. The chemical structure of PEEK material [11].

Technologies and Materials for Renewable Energy, Environment and Sustainability AIP Conf. Proc. 2123, 020065-1-020065-9; https://doi.org/10.1063/1.5116992 Published by AIP Publishing. 978-0-7354-1863-9/\$30.00 
Bakar et al fabrication hydroxyapatite and polyetheretherketone ranges from 5 to $40 \mathrm{vol} \%$. It was found that the amount of HA in the composite influenced the tensile properties. Dynamic behavior under tension-tension fatigue revealed that the fatigue-life of PEEK-HA composites were dependent on the HA content as well as the applied load. The biological behavior of the composite was verified by in vivo assays and the results indicated a high bioactivity of the composite [12].

$\mathrm{Wu}$ et al prepared n-TiO2/PEEK nanocomposites, the in vitro and in vivo bioactivity of these nanocomposites was assessed and there results show that bioactivity evaluation of the nanocomposites revealed that pseudopods of osteoblasts preferred to anchor at areas where n-TiO2 was present on the surface [13].

Wang et al successfully examined mechanical properties and microstructure of polyetheretherketone (PEEK-hydroxyapatite) nanocomposite materials. The specimens laminated by composites with 5 vol.\% and 15 vol.\% HA which gave a promising mechanical strength and a high HA content on the specimen surface [14].

Wang et al. incorporated nano-FHA into PEEK in order to enhance its antibacterial property and osseointegration of implant materials. Mechanical tests revealed that nano-FHA acts as reinforcement filler in PEEK considering that both $\mathrm{E}$ and tensile strength increased in $210 \%$ and $67 \%$, respectively, with the incorporation of $40 \mathrm{wt} \%$ nano-FHA into PEEK. Furthermore, microbiological assays indicated that the composite possesses an antibacterial activity. The in vivo assays showed high bioactivity, osseointegration and bone-implant contact [15].

Deng et al developed a PEEK ternary composite by adding nano-HA and CF into the polymer. The incorporation of $25 \mathrm{wt} \%$ nano-HA and $20 \mathrm{wt} \%$ CF into PEEK increased the E and tensile strength in approximately $371 \%$ and $52 \%$, respectively. The biological assays showed a higher cell attachment, proliferation and osteogenic differentiation than those recorded for PEEK [16].

Vaezi et al used a novel production technique based on the extrusion freeforming method is proposed that yields a bioactive PEEK/hydroxyapatite (PEEK/HA) composite with a unique configuration. The PEEK/HA biocomposites produced exhibited a good biocompatibility and cell attachment, while incorporation of HA into PEEK could result in reduction of mechanical properties [17].

Schwitalla et al. studied the fatigue limits of different composite materials based on (PEEK) using different PEEK materials of various grades: unfilled, filled with $(10-20) \%$ titanium dioxide or $(6-20) \%$ barium sulfate powder, reinforced with (30)\% short carbon fibers or short glass fibers, and reinforced with $(50) \%$ multi continuous carbon fibers and $(>50) \%$ unidirectional continuous carbon fibers. It was found that all the tested PEEK compounds appear capable of withstanding axial pressure caused by the mastication process [18].

Oliveira et al illustrated the influence of the plasma spray process on the fatigue behavior of PEEK under deformation-controlled three-point bending tests using three distinct thermal conditions for PEEK: (i) "as molded", (ii) plasma-exposed only and (iii) HA-coated. demonstrated that the plasma spray process had a minor positive effect on the fatigue stress decay rate, with a slight reduction in this rate for the plasma exposed and HA coated PEEK samples[19].

\section{PEEK COMPOSITE STRATEGIES}

PEEK composites are fabricated by blending with second phase constituents (fibers or particles) for expected performance. Reinforced fibers (e.g. glass and carbon fibers) are used to improve the mechanical properties of PEEK and bioactive particles are considered to be used to improve the bioactivity. Both mechanical properties and bioactivity of PEEK-based composites could be improved for long-term implantation [20]. Hydroxyapatite (HA), $\left[\mathrm{Ca}_{10}\left(\mathrm{PO}_{4}\right)_{6}(\mathrm{OH})_{2}\right]$, is a calcium phosphate mainly known for its applications in bone replacement [21]. Hydroxyapatite (HA) reinforced polymer composites have received much attention in recent years especially in the field of biomedical materials. Unlike conventional implant materials such as stainless steel and cobalt-chromium alloys, the next generation of biomaterials (e.g. HA reinforced polymer composites), with the inclusion of bioactive HA not only matches the mechanical properties (i.e. stiffness and strength) of bone but also mimics bony tissue by generating a biological response that promotes bone growth on the implant [22]. Titanium dioxide $\left(\mathrm{TiO}_{2}\right)$ is well known as biologically and chemically inert, mechanically robust, nontoxic, cheap, biocompatible, antifogging and super-hydrophobic [23]. $\mathrm{TiO}_{2}$ is widely used in environmental applications, cosmetics, paper, coatings, foods, toothpastes and paint because of its green, clean, low cost and sustainable innovation also often used as the reinforcement phase of polymer matrix to improve its mechanical properties [24]. The present work aimed at developed a novel polymer biocomposites reinforced with nano bioceramic for the enhancement of the mechanical properties as a potential bioactive material used as implants in human body.

\section{MATERIALS and METHODS}

\section{SAMPLE PREPARTION}

PEEK(551G) pellets, Nano hydroxyapatite and Nano titanium dioxide were purchased from (Jilin Joinature Polymer Co., Ltd, china), (N \& R Industries, Inc, China) and (Hangzhou Union Biotechnology Co., Ltd, china) respectively. The two nano particles have $20 \mathrm{~nm}$ particle size. The biopolymer composites containing $(0,0.5,1,1.5) \mathrm{wt} \%$ for two types of nano powder were 
fabricated via a series of processes compounding and hot press process. PEEK pellets were dried in an oven $80{ }^{\circ} \mathrm{C}$ for $1 \mathrm{hr}$ prior to compounding and hot press. In brief, nano powder were dispersed in ethanol alcohol using ultrasonic mixer with variables $(90$ W power, 0.5 pulse and (5-10)min) to obtain a homogeneous mixture and then mixing with PEEK pellets. After well dispersed, the mixture was dried in a oven at $90{ }^{\circ} \mathrm{C}$ for $24 \mathrm{~h}$ to remove the excess ethanol alcohol. In the compounding process, Compounding was carried out in an internal mixer (Haake) type (HBISYSTEM 90, AHAAKE BUCHLER PRODUCT, USA) at temperature of $360^{\circ} \mathrm{C}$ and mixing speed at $90 \mathrm{rpm}$. The time needed for compounding was adjusted accordingly 20 min. then hot press by using mold with dimension $\left(17^{*} 17^{*} 0.4\right) \mathrm{cm} 3$ was preheated at temperature $200^{\circ} \mathrm{C}$ and covered from the top and bottom by a cover withstand a high temperature in order to prevent adhesion of polymeric composite to mold and put in hot press type (TOYOSEIKI, Japan). Temperature in hot press was adjusted at $360^{\circ} \mathrm{C}$ when reaching this temperature the pressure was applied for (15) min and its value equal (15MPa). The mould was then removed from hydraulic press and put in cooling system cooled with water jet $(5 \mathrm{~L} / \mathrm{min})$ at temperature room temperature. The mould was opened, and then the composite sheet was removed and cutting the specimens by $\mathrm{CNC}$ machine for each test as show in figure (2).

The preparation of polymer composites and tensile test was done in Iran Polymer and Petrochemical Institute while nanoindentation test was done in university of Tehran.

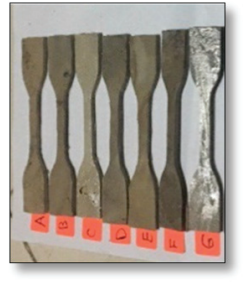

(a) Specimen for tensile test

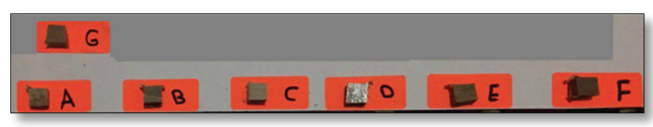

(b) Specimen for nanindentation test

FIGURE 2. Specimens for inspection.

\section{TENSILE TEST}

The experimental tensile test was performed on the tensile test machine (SANTAM, type STM-50, Iran) figure (3) with an ASTM D638 type IV standard [25, 26].The parameters for setting up the experiment were as follows: Tensile speed $5 \mathrm{~mm} / \mathrm{min}$, cross head speed $0.1 \mathrm{~mm} / \mathrm{min}$ and room temperature $\left(25^{\circ} \mathrm{C}\right)$ in order to obtain the best results 3 specimens were tested for each of the filler ratios.

\section{NANOINDENTATION TEST}

The elastic modulus and hardness of biopolymer composites were obtained from nanoindentation testing (Triboscope, nanomechanical test instrument, HYSITRON, Inc, USA) as shown in Figure (4) with a pyramid- shaped Berkovich indenter which is nominally a three sided pyramid with a half angle of 65.35. The samples for the nanoindentation are a flat plate with a size of $(1 * 1 * 0.4) \mathrm{cm} 3$. Indentation experiment has been used for more than a century to measure mechanical properties of materials. The principle is simple, a tip supposed non-shrinking is pressed against the test materials. In this technique a series of 5 indents was performed for each sample the peak load of the indenter was adjusted to maintain loading, unloading and holding times. The first stage is an approach stage of the indenter to the surface of specimen. Following this, the loading stage was applied. The next stage of nanoindentation testing was a holding stage followed by an unloading stage. The time for each stage is $5 \mathrm{sec}$. 


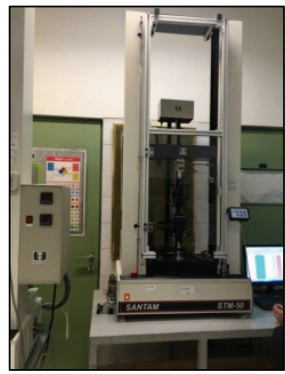

FIGURE 3. Tensile test instrument.

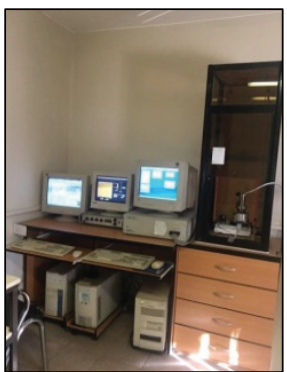

FIGURE 4. Nanoindentation test instrument.

\section{PROCEDURE USED to CALCULATE THE ELASTIC MODULUS}

This device is used to designate the nanomechanical properties of materials, such as hardness and Young's modulus. After each complete cycle consisting of the loading and unloading of the sample it is plotted a graph load of the indenter as a function of penetration depth displacement - as in Figure (5),

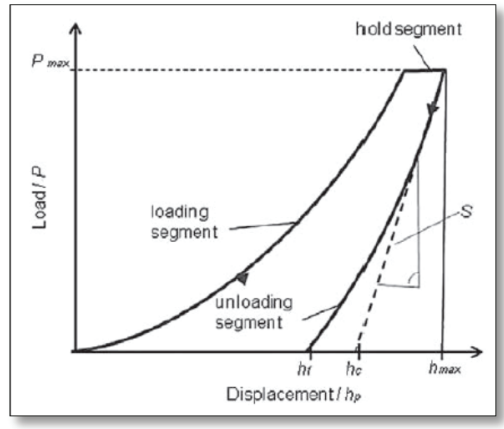

FIGURE 5. Typical loading-penteration depth curve [27].

where: $\mathrm{P}$ - load, $\mathrm{h}_{\mathrm{c}}$-penetration depth, $\mathrm{h}_{\mathrm{f}}$ - residual depth, $\mathrm{h}_{\mathrm{c}}$-contact depth, $\mathrm{h}_{\max }$ - maximal depth, $\mathrm{S}$ - contact stiffness. The analysis of the results indentation experiment was based on Oliver and Pharr method as explain in the following relationships [27]:

- reduced modulus:

Where:

$$
\frac{1}{E^{*}}=\frac{1-v^{2}}{E}-\frac{1-v^{\prime 2}}{E^{\prime}}
$$

E - modulus of specimen,

E' - modulus of intender

$v$ - Poisson's ratio.

- stiffness:

- hardness:

$$
S=\frac{\mathrm{dP}}{\mathrm{dh}}=2 \mathrm{E}^{*} \frac{\sqrt{\mathrm{A}}}{\sqrt{\mathrm{P}}}
$$

- contact area:

$$
H=\frac{P}{24.5 h_{p}^{2}}
$$

$$
\mathrm{A}=3 \sqrt{3 \mathrm{~h}_{\mathrm{p}}^{2}} \tan ^{2} 65.3=24.5 \mathrm{~h}_{\mathrm{p}}^{2}
$$


Where:

$\mathrm{h}_{\mathrm{p}}$-penetration depth.

- elastic modulus:

$$
E^{*}=\frac{d P}{d h} \frac{1}{2 h_{p} \beta} \sqrt{\frac{\pi}{24.5}}
$$

$\beta=1.034$ for Berkovich intender.

\section{RESULTS AND DISCUSSION}

\section{TENSILE BEHAVIOR OF NANOCOMPOSITE}

The results of tensile tests is shown in figures $(6 \& 7)$. It is observed that the addition of (n $\mathrm{HA} \&$ nTiO $\left._{2}\right)$ as reinforcement, increased in young's modulus and ultimate tensile strength of composite materials with increasing weight percentage of reinforcement. This is attributed to better bonding between the polymer matrix and the reinforcing phase resulted in a higher elastic modulus and higher tensile strength [14]. Obviously, the higher content of reinforcement causing a stiffer overall material which lead to increase of the load carrying capacity of composite materials. The results showed that the maximum value of young's modulus and tensile strength of HA (5.961 GPa \& 79.457MPa) respectively, while the maximum value of young's modulus and tensile strength of $\mathrm{TiO}_{2}(4.631 \mathrm{GPa}, 74.692 \mathrm{MPa})$ respectively [28]. Additionaly, The modulus of elasticity and tensile strength of composites with the addition of nHA is higher than that for composite with $\mathrm{n} \mathrm{TiO}_{2}$. Therefore, a polynomial fit was performed on the data to render a better quantitative description. From this polynomial equation a strong correlation $\left(\mathrm{R}^{2}=0.9935,0.9903,0.9999\right.$ and 0.9985$)$ for nHA reinforced polymer and $\mathrm{nTiO}_{2}$ reinforced polymer respectively. These results also agree with the results obtained in reference [29].

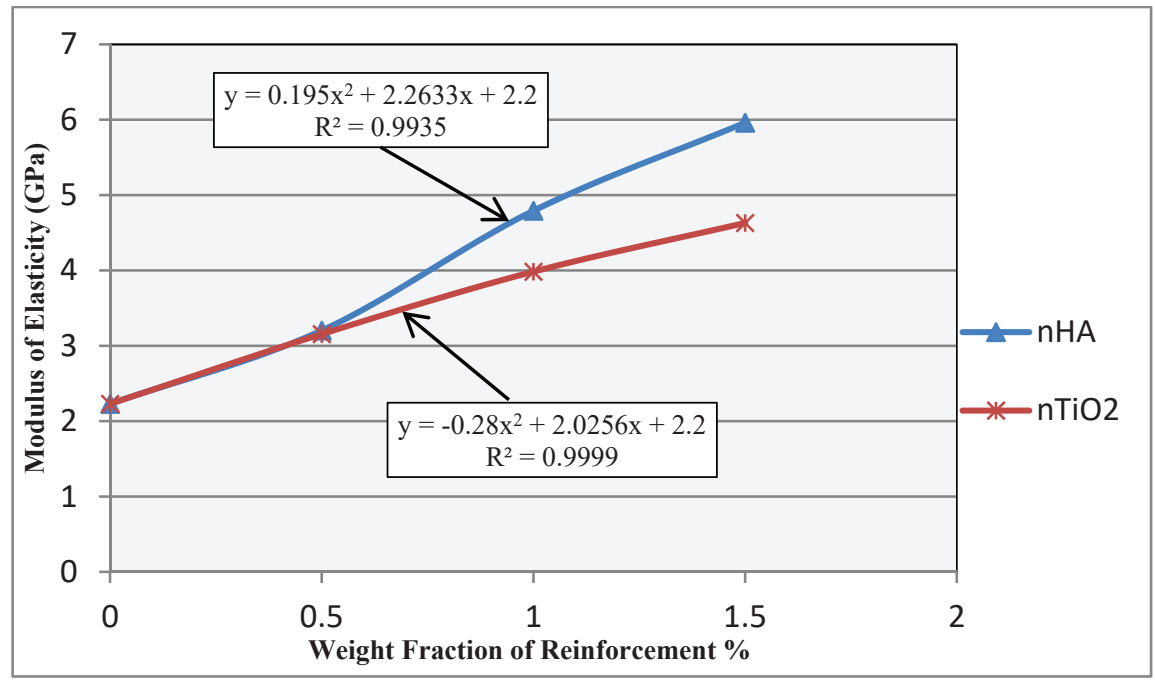

FIGURE 6. Modulus of elasticity for tensile test. 


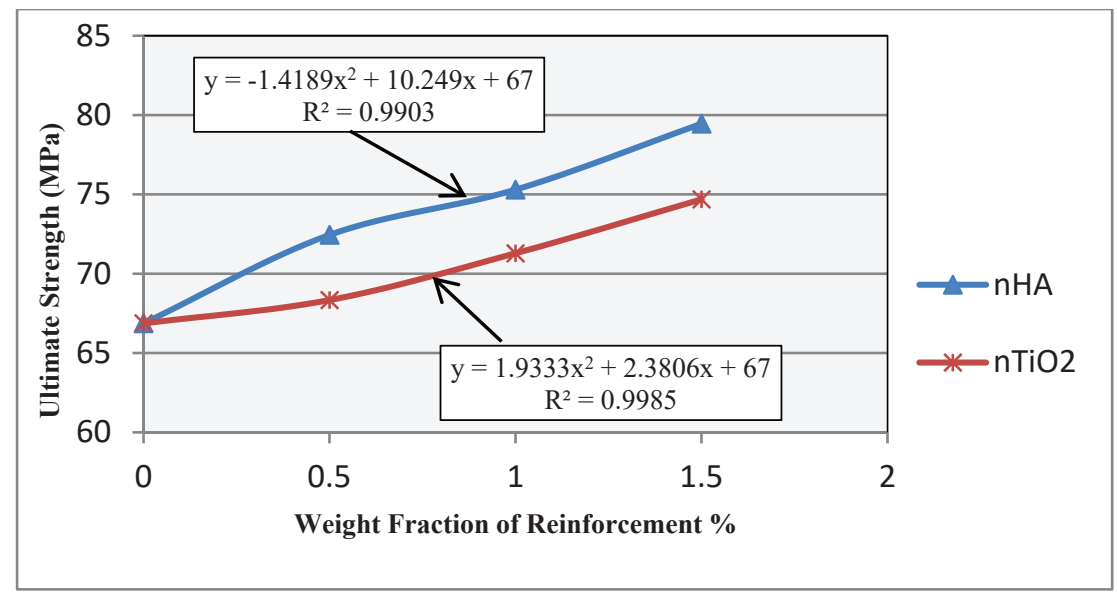

FIGURE 7. Ultimate strength for tensile test.

\section{NANOINDENTATION BEHAVIOR OF NANOCOMPOSITE}

Figure (8) demonstrate the modulus of elasticity for nanocomposites increases with the increase of nano particles incorporated into the polymer matrix. The $1.5 \%$ from nano particles incorporated into PEEK polymer showed a significantly higher elastic modulus compared to all other percentage of nano particles incorporated samples. Moreover, the modulus of elasticity for nanocomposites are all larger than those of the neat PEEK. This is explained by the higher content of reinforcement causing a stiffer overall material. It means nanocomposites has higher stiffness and can offer a higher resistance to deformation than neat PEEK does [30]. Furthermore the for hardness of nanoparticles incorporated samples was shown in figure (9) follow the same trend as the modulus of elasticity, the average hardness aslo increases with increased percentage of nanoparticles in samples, the $1.5 \%$ has the highest average hardness among all the other samples[31]. Also it clearly can be seen the modulus of elasticity and hardness was obtained from composites reinforced with $\mathrm{nHA}$ is higher than that for composite reinforced with $\mathrm{nTiO}_{2}$. Therefore, a polynomial fit was performed on the data to render a better quantitative description. From this polynomial equation a strong correlation $\left(\mathrm{R}^{2}=0.9819,0.9845,0.9088\right.$ and 0.9651$)$ for $\mathrm{nHA}$ reinforced polymer and $\mathrm{nTiO}_{2}$ reinforced polymer respectively. The results of two techniques showed increase in modulus of nanocomposite samples as compared to the pure samples. These results contradict the theory that nanoparticle fillers improve the composites mechanical properties, specifically the elastic modulus. However, a noticeable difference in elastic modulus was obtained from the nanoindentation experiments as compared to the tensile tests, as show in figures $(10 \& 11)$. Clearly with the nanoindentation testing technique the elastic modulus obtained higher than the one obtained from the tensile test. It can be seen in table (1) that there are large differences in the values. Tensile modulus are about (14-38)\% lower than those from nanoindentation [32]. It is very important for implant to match the elastic modulus of implant materials with human bone. As shown in these figures, when compare the modulus of elasticity obtained from tensile and nanoindentation techniques the modulus value of the pure PEEK, $0.5 \%$ nano particles and $1 \%$ nanoparticles respectively was lower than that of human cortical bone (6-30GPa) while the modulus of elasticity of $1.5 \%$ nano particles reinforced PEEK was within the range of 6-30GPa (the modulus value of human cortical bone (6-30GPa) [33].

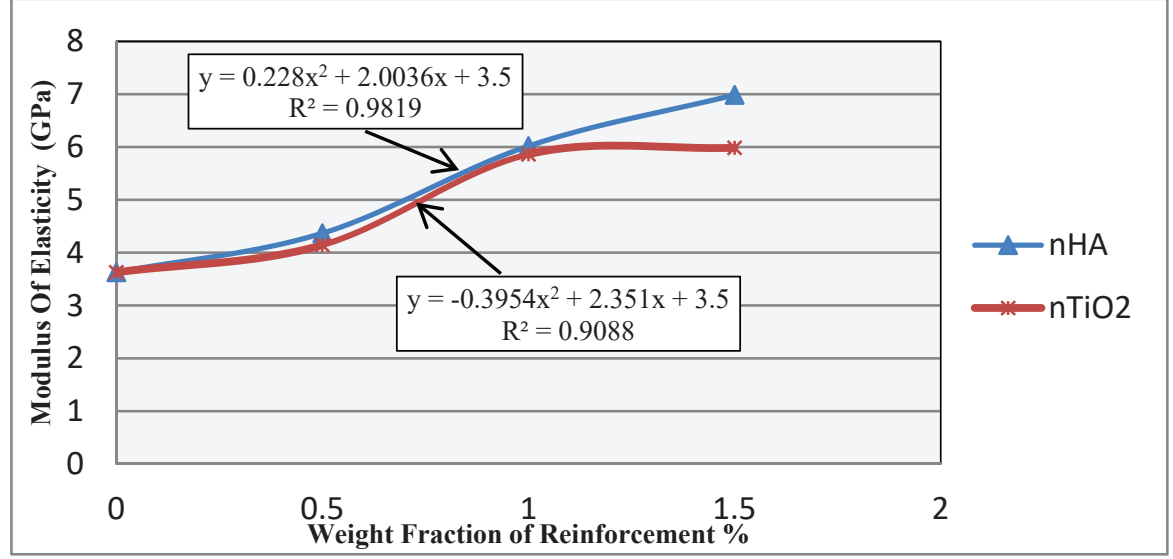

FIGURE 8. Modulus of elasticity for nanoindentation test. 


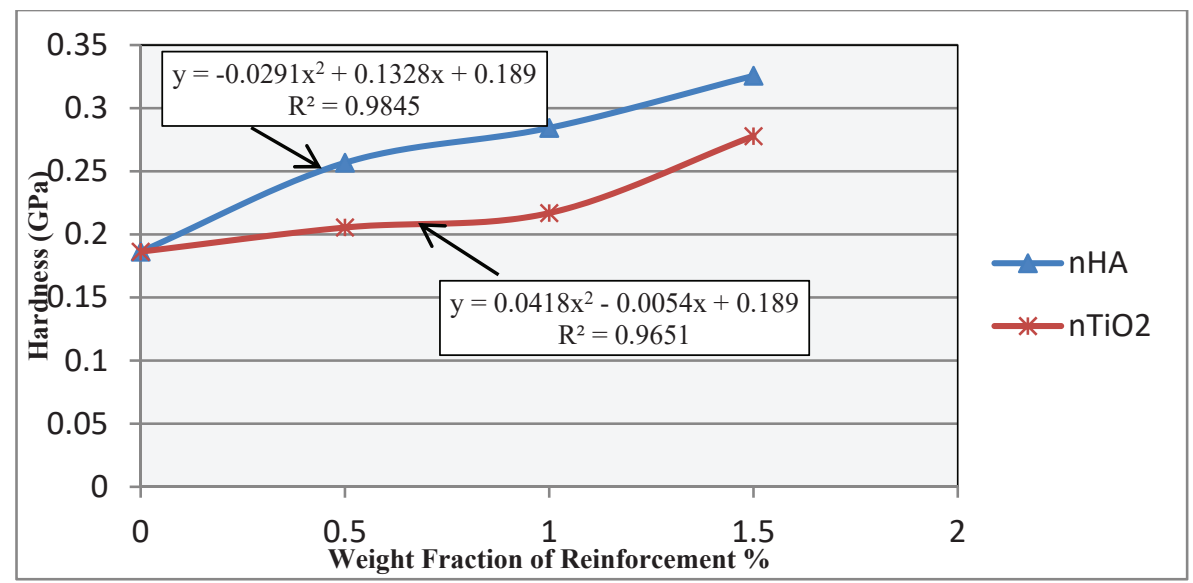

FIGURE 9. Hardness for nanoindentation test.

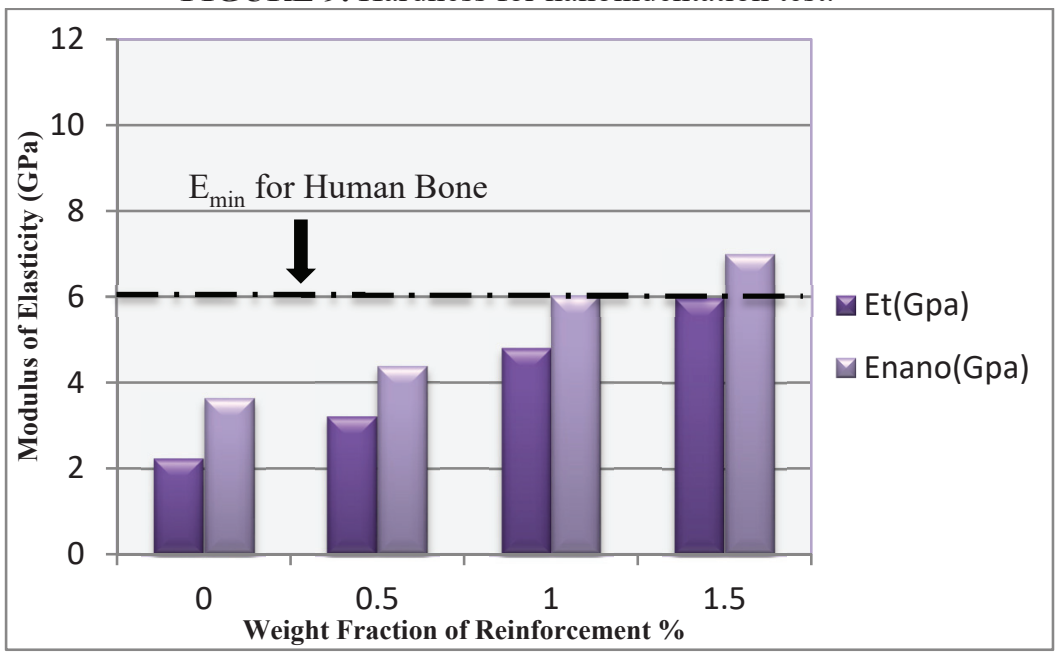

FIGURE 10. Comparison the elastic modulus obtained from nanoindentation and tensile test results for composites reinforced with nano hydroxyapatite.

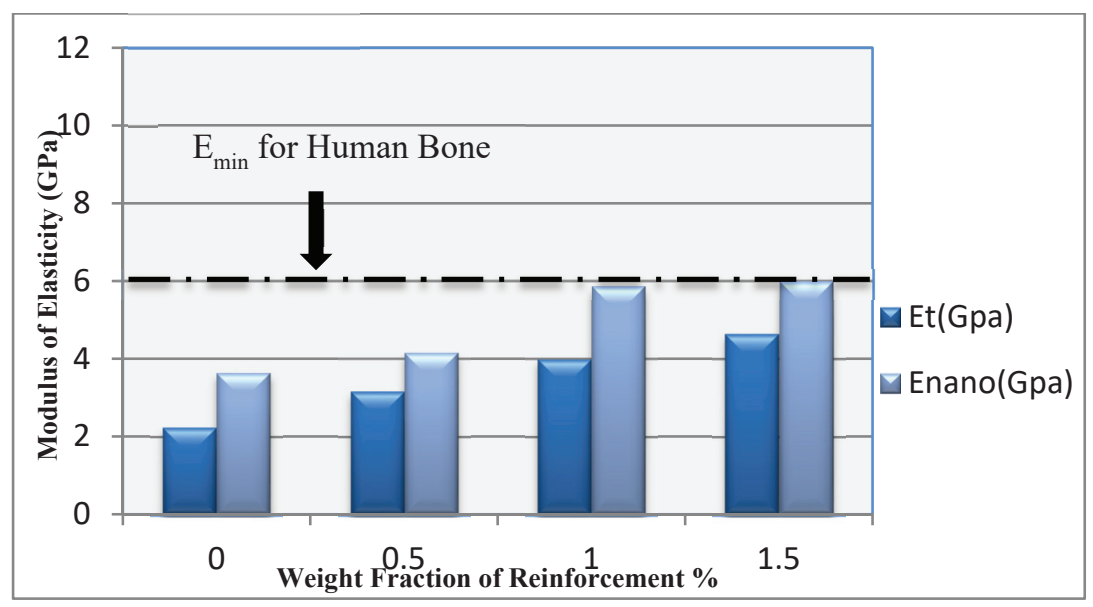

FIGURE 11. Comparison the elastic modulus obtained from nanoindentation and tensile test results for composites reinforced with nano titanium oxide. 
TABLE 1. Differences between nanoindentation and tensile test results.

\begin{tabular}{ccccccc}
\hline \multirow{2}{*}{ Sample } & \multicolumn{2}{c}{$\mathbf{n H A}$} & & \multicolumn{2}{c}{$\mathbf{n T i O}_{\mathbf{2}}$} & \\
\cline { 2 - 3 } & $\begin{array}{c}\mathbf{E}_{\text {nano }} \\
\mathbf{G P a})\end{array}$ & $\begin{array}{c}\mathbf{E}_{\mathbf{t}} \\
\mathbf{G P a})\end{array}$ & Differences & $\mathbf{E}_{\text {nano }}(\mathbf{G P a})$ & $\begin{array}{c}\mathbf{E}_{\mathbf{t}} \\
\mathbf{( G P a})\end{array}$ & Differences \\
$0 \%$ & 3.6289006 & 2.231 & 0.385 & 3.6289006 & 2.231 & 0.385 \\
$0.5 \%$ & 4.3685317 & 3.204 & 0.267 & 4.1458128 & 3.157 & 0.239 \\
$1 \%$ & 6.0200732 & 4.793 & 0.204 & 5.8643186 & 3.985 & 0.32 \\
$1.5 \%$ & 6.9877005 & 5.961 & 0.147 & 5.9858144 & 4.631 & 0.226 \\
\hline
\end{tabular}

\section{CONCLUSIONS}

In this study, the nanoindentation test and tensile test is performed on Polyetheretherketone reinforced by two nanoceramic with different weight fraction the following conclusions can be extracted:

1. Elastic modulus, ultimate tensile strength and hardness showed an increased trend with increased weight fraction of reinforcement.

2. Higher value for mechanical properties obtained when reinforced with nanohydroxyaptite.

3. The elastic modulus obtained by nanoindentation different by (14-38)\% from elastic modulus obtained by tensile test.

\section{ACKNOWLEDGMENTS}

The authors greatly acknowledge the University of Technology / Baghdad-Iraq, Iran Polymer and petrochemical institute and university of Tehran for their support.

\section{REFERENCES}

1. A. Jonas, R. Legras and J.P. Issi, J. of Polymer, 32, 3364-3370, (1991).

2. Y.C. Ke, Y.B. Zheng and Z.W.Wu, Chin. J. Mater. Res., 10, 205-209, (1996).

3. C.S. Michacl, E.M. James, G.B. Jennifer, M.K. Steve and M.R. Clare, Biomaterials, 31, 9156-9162, (2010).

4. X.Z.K. Loy and S.K. Sinha,Wear, 296, 681-692, (2012).

5. X.Q. Pei, B. Roland and B. Michael,Wear, 304, 109-117, (2013).

6. A. Godara, D. Raabe and S. Green, Acta Biomater, 3, 199-220, (2007).

7. D.J. Jaekel, D.W. Macdonald and S.M. Kurtz, J. Mech. Behav. Biomed. Mater., 4, 1275-1282, (2011).

8. F.E.I. Halabi, J.F. Rodriguez, L. Rebolledo, E. Hurtos and M. Doblare, J. Mech. Behav. Biomed. Mater., 4 1819-1832, (2011).

9. Y. Pan, Y.Chen \& Q. Shen, J. of Mater. Sci. \& Tech., 32, 34-40, (2016).

10. L. Eschbach, Injury, 31, 22-27, (2000).

11. S. Tekin, S. cangul, O. Adiguzel and Y. Deger, Inter. Den. Res., 8, 84-92, (2018).

12. M. S. Abu Bakar, M.H. W. Cheng, S. M. Tang, S. C. Yu, K. Liao, C. T. Tan, K. A. Khor and P. Cheang, Biomaterials, 24, 2245-2250, (2003).

13. X. Wu, X. Liu, , J. Wei, J. Ma, F. Deng and S.Wei, Inter. J. Nanomedic., 7, 1215-1225, (2012).

14. L. Wang, L. Weng, S. Song and Q. Sun, Mater. Letters 64, 2201-2204, (2010).

15. L. Wang, S. He, X. Wu, S. Liang, Z. Mu, J. Wei, Biomaterials, 35, 6758-6775, (2014).

16. Y. Deng, P. Zhou, X. Liu, L. Wang, X. Xiong and Z. Tang, Colloids Surf. B. Biointerfaces, 136, 64-73, (2015).

17. M. Vaezi, C. Black, D. M. R. Gibbs, R. O. C. Oreffo, M. Brady, M. M. Torbati and S. Yang, Molecules, 687, 1-21, (2016).

18. A. D. Schwitalla, T. Zimmermann, T. Spintig, I. Kallage and W. Müller, J. Mech. Behav. Biomed. Mater., 69, 163168, (2017).

19. T. P. Oliveira, S. N. Silva and J. A. Sousa, Inter. J. Fat., 108, 1-8, (2018).

20. Y. W. Du, L. N. Zhang, Z. T. Hou, X. Ye, H. S. Gu, G. P. Yan and P. Shang, Front. Mater. Sci., 8, 313-324, (2014).

21. J. Kolmas, S. Krukowski, A. Laskus and M. Jurkitewicz, Ceram. Int., 42, 2472-2487, (2016).

22. M.S. Abu Bakar, P. Cheang \& K.A. Khor, J. Mater. Proc. Tech, 89-90, 462- 466, (1999).

23. S. Yousefali, A. Reyhani, S. Z. Mortazavi, N. Yousefali and A.Rajabpour, Surfaces and Interfaces, 13, 11-21, (2018).

24. S. Shi, D. Shen, T. Xu and Y. Zhang, Composites Science and Technology, 164, 17-23, (2018). 
25. ASTM International, D 638-2002a, "Standard test method for tensile properties of plastics".

26. J. K. Oleiwi, E. S. Al-Hassani and A. A. Mohammed, Eng. \& Tech. Journal, 32, 653-666, (2014).

27. G. Galuszka, M. MadEej, D. Ozimina, J. Kasinska and R. Galuszka, Metalurgija, 56, 191-194, (2017).

28. M. Yunus \& M. S.Alsoufi, International Journal of Biomaterials, 1-8, (2018)

29. A. A. Mohammed, Eng. and Tech. Journal, 33, 919-933, (2015).

30. B. K. Barnes, A. J. Bow, G.Kannarpady, A. S. Biris, D. E. Anderson, M. Dhar and S. E. Bourdo, Journal of Biomaterials Science, Polymer Edition, 29, 1426-1443, 2018.

31. A. C. Jayasuriya, A. Aryaei and A. H. Jayatissa, Materials Science and Engineering C, 33, 3688-3696, (2013).

32. J. Nemecek, Key Engineering Materials, 586, 55-58, (2014).

33. W. Qin, J. Ma, Y. Li, Q. Liang \& B. Tang, J. Mech. Behav. Biomed. Mater., 89, 227-233, (2019). 